\title{
Survival and Operative Outcomes After Salvage Surgery for Recurrent or Persistent Anal Cancer
}

\author{
In Ja Park ${ }^{1}$, George Chang ${ }^{2}$ \\ ${ }^{1}$ Department of Colon and Rectal Surgery, Asan Medical Center, University of Ulsan College of Medicine Seoul, Korea; ${ }^{2}$ Department of Colon \\ and Rectal Surgery, University of Texas MD Anderson Cancer Center, Houston, TX, USA
}

Anal squamous cell carcinoma (SCC) is a relatively rare cancer comprising less than $2.5 \%$ of all gastrointestinal malignancies. The standard treatment for anal SCC is primary chemoradiation therapy which can result in complete regression. After successful treatment, the 5-year survival is approximately $80 \%$. However, up to $30 \%$ of patients experience recurrent persistent or recurrent disease. The role of surgery in the treatment of anal cancer, therefore, is limited to the management of recurrent or persistent disease with abdominoperineal resection and/or en bloc adjacent organ excision. Salvage surgery after irradiated anal cancer can be technically demanding in terms of acquisition of oncologically safe surgical margins and minimization of postoperative morbidity. In addition, 5-year survival outcomes after salvage resection have been reported to vary from $23 \%$ to $69 \%$. Positive resection margins are generally regarded as the important risk factor associated with poor survival outcome. Perineal wound complications are the most common major postoperative morbidity. Because of the challenges of primary wound closure after salvage abdominoperineal resection, myocutaneous flap reconstruction has been performed to reduce the severity of perianal would complications. We, therefore, descriptively reviewed contemporary published evidence describing the treatment and outcomes after salvage surgery for persistent or recurrent anal SCC.

\section{Keywords: Anal cancer; Squamous cell; Recurrent; Persistent; Salvage}

\section{INTRODUCTION}

Anal cancer is rare, but in the last 2 decades, the incidence has been increasing. The annual incidence of anal squamous cell carcinoma (SCC) has been steadily increasing over the past 10 years. According to the International Agency for Research on Cancer of World Health Organization, anal cancers made up approximately $0.3 \%$ of new cancers and had an estimated 48.5 new cases of anal cancer developed 1,000 in both sexes per year in 2018 [1]. More than $90 \%$ of patients will have the locoregional disease at presen-

Received: Dec 15, 2020 - Revised: Dec 26, 2020 - Accepted: Dec 29, 2020 Correspondence to: In Ja Park, M.D.

Department of Colon and Rectal Surgery, Asan Medical Center, University of Ulsan College of Medicine, 88 Olympic-ro 43-gil, Songpa-gu, Seoul 05505, Korea

Tel: +82-2-3010-3937, Fax: +82-2-3010-6701

E-mail: ipark@amc.seoul.kr

ORCID: https://orcid.org/0000-0001-5355-3969

(C) 2020 The Korean Society of Coloproctology

This is an open-access article distributed under the terms of the Creative Commons Attribution NonCommercial License (https://creativecommons.org/licenses/by-nc/4.0) which permits unrestricted noncommercial use, distribution, and reproduction in any medium, provided the original work is properly cited. tation with overall locoregional failure rates of $20 \%$ to $35 \%$ and distant failure rates of approximately $15 \%$ to $20 \%[2,3]$. Most anal cancers (80\%) are SCC and are associated with human papillomavirus (HPV) infection. Other factors associated with increased risk of anal cancer include multiplicity of sexual partners, history of cervical dysplasia, and smoking [4]. Immunosuppressions by human immunodeficiency virus infection or after organ transplantation or cancer chemotherapy have also been associated with an increased risk for anal SCC $[5,6]$. Chronic irritation in anal cancer from benign conditions, such as fistulae, was believed to be associated with the development of anal SCC; however, there is little solid evidence for such associations.

It is now well recognized that sexually transmitted infection by HPV plays a major role in the development of SCC of the anal canal. HPV serotypes 16 and 18 have been most frequently associated with the development of invasive disease; however, multiplicity of infection appears to also play an important role [7-9]. Indolent HPV infection is associated with an increased risk for development of anal cancer, and this effect will be most significant in immunocompromised patients. These factors may have implications for salvage surgical management of recurrent or persistent 
disease.

Although there is emerging promising data with immunotherapy for recurrent/persistent anal cancer, it is not yet enough to replace the definitive salvage surgery; therefore, this review focuses the discussion on salvage surgery.

\section{PRIMARY TREATMENT OF ANAL CANCER AND INCIDENCE OF RECURRENT/ PERSISTENT ANAL CANCER}

Since Nigro's description of the primary efficacy of chemoradiotherapy (CXRT) for anal cancer, the primary treatment of anal cancer has remained definitive CXRT [10]. The administration of combined modality CXRT was originally developed as a neoadjuvant strategy, but the results without subsequent resection were unexpectedly favorable. In fact, CXRT offers 5-year survival rates of up to $90 \%$, with local control in $70 \%$ to $90 \%$ of patients $[2,3$, $11,12]$. The standard radiation field includes the pelvis, anus, perineum, and inguinal nodes. The typical dose of radiation given varies between 45 and 59 Gy dependent upon the stage and distribution (e.g., lateral or inguinal lymph nodes [LNs]) of the primary and locoregional disease. Accepted standards for concurrent chemotherapy include fluoropyrimidine with mitomycin- $\mathrm{C}$ or cisplatin.

Failure to achieve a complete clinical response to combination CXRT occurs in $10 \%$ to $15 \%$ of patients, while an additional $10 \%$ to $15 \%$ of patients will develop tumor recurrence after an initial response Table 1 [2, 11-15]. Most authors have defined persistent disease as the diagnosis of histological confirmation of anal cancer within 6 months after completion of CXRT. Recurrent disease has been considered when diagnosed at least 6 months after a complete clinical response and preceded by an interval without clinical evidence of cancer. Thus, disease apparent between 6 and 12 months may still represent persistent disease, particularly if the initial tumor was bulky or ulceration at the site never fully resolved. Failure to achieve a complete clinical response to CXRT portends a poor prognosis. Whether recurrent as opposed to persistent disease after CXRT predicts survival has been debated in the literature Table 2 [16-33]. But, because of the paucity of literature on outcomes after salvage abdominoperineal resection (APR), and difficulty in determination whether disease is recurrent or persistent, this may remain an unresolved issue with respect to the diagnosis, salvage treatment, and outcomes of recurrent or persistent anal cancer.

Therefore, the principles of operative salvage therapy of recurrent/ persistent anal cancer and the associated management challenges and outcomes will be reviewed.

\section{DIAGNOSIS OF RECURRENT/PERSISTENT ANAL CANCER}

No consensus has been reached on appropriate follow-up after

Table 1. Result of randomized phase III trials of anal cancer treatment

\begin{tabular}{|c|c|c|c|c|c|c|c|c|}
\hline Study & Period & Design & $\begin{array}{l}\text { No. of } \\
\text { subject }\end{array}$ & $\begin{array}{l}\text { Median } \\
\text { follow-up } \\
\text { (mon) }\end{array}$ & $\begin{array}{l}\text { Complete } \\
\text { remission } \\
(\%)\end{array}$ & $\begin{array}{l}\text { DFS } \\
(\%)\end{array}$ & $\begin{array}{l}\text { Local failure } \\
\text { rate }(\%)\end{array}$ & $\begin{array}{l}\text { Site of initial } \\
\text { failure (\%) }\end{array}$ \\
\hline ACT I (UKCCCR) [11] & 1987-1994 & RT only vs. CRT & 585 & 42 & $\begin{array}{l}30 \text { (RT) } \\
39 \text { (CRT) }\end{array}$ & No data & $\begin{array}{l}\text { At } 3 \text { yr } \\
61(\mathrm{RT}) \\
39(\mathrm{CRT})\end{array}$ & No data \\
\hline ACT II (UKCCCR)[12] & 2001-2008 & 5FU/MMC/RT vs. 5FU/Cis/RT & 940 & 36 & $\begin{array}{l}94.5 \text { (MMC) } \\
95 \text { (Cis) }\end{array}$ & At $3 \mathrm{yr}, 73$ & $\begin{array}{l}11 \text { (MMC) } \\
13 \text { (Cis) }\end{array}$ & No data \\
\hline EORTC 22861 [13] & 1987-1994 & RT vs. CRT & 110 & 42 & $\begin{array}{l}54(\mathrm{RT}) \\
80 \text { (CRT) }\end{array}$ & No data & $\begin{array}{l}\text { At } 5 \text { yr } \\
50(\mathrm{RT}) \\
32(\mathrm{CRT})\end{array}$ & $\begin{array}{l}\text { LR only: } 28.8 \text { (RT), } 11.8 \text { (CRT) } \\
\text { LR+DM: } 19.2 \text { (RT), } 17.6 \text { (CRT) } \\
\text { DM only: } 1.9 \text { (RT) }\end{array}$ \\
\hline RTOG 8704 [14] & 1988-1991 & 5FU/RT vs. 5FU/MMC/RT & 291 & 36 & $\begin{array}{l}86(5 \mathrm{FU}) \\
92.2(\mathrm{MMC})\end{array}$ & $\begin{array}{l}\text { At } 4 \text { yr, } \\
51 \text { (5FU) } \\
73 \text { (MMC) }\end{array}$ & At $4 \mathrm{yr}, 16$ & No data \\
\hline RTOG 9811 [2] & 1998-2005 & 5FU/Cis/RT vs. 5FU/MMC/RT & 644 & 30 & No data & $\begin{array}{l}\text { At } 5 \mathrm{yr}, \\
60 \text { (MMC) } \\
54 \text { (Cis) }\end{array}$ & $\begin{array}{l}25 \text { (MMC) } \\
33 \text { (Cis) }\end{array}$ & $\begin{array}{l}\text { LR:13 (MMC), } 19 \text { (Cis) } \\
\text { Regional: } 6 \text { (MMC), } 7 \text { (Cis) } \\
\text { DM: } 6 \text { (MMC), } 9 \text { (Cis) }\end{array}$ \\
\hline ACCORD-03 [15] & 1999-2005 & $\begin{array}{l}2 \times 2 \text { factorial } \pm 5 F U / C i s ~ n e o a d j u v a n t ; \\
15 / 20-25 \text { Gy boost }\end{array}$ & 307 & 43 & $74-86$ & $67-78$ & $\begin{array}{l}\text { At } 3 \mathrm{yr} \text {, } \\
\text { overall } 12\end{array}$ & No data \\
\hline
\end{tabular}

DFS, disease-free survival; ACT I (UKCCCR), the first randomized UKCCCR Anal Cancer Trial; ACT II (UKCCCR), the second randomized UKCCCR Anal Cancer Trial; EORTC, European Organisation for Research and Treatment of Cancer; RTOG, Radiation Therapy Oncology Group; ACCORD, Action to Control Cardiovascular Risk in Diabetes; RT, radiotherapy; CRT, chemoradiation; 5FU, 5-fluorouracil; MMC, mitomycin; Cis, cisplatin; LR, local recurrence; DM, diabetes mellitus. 


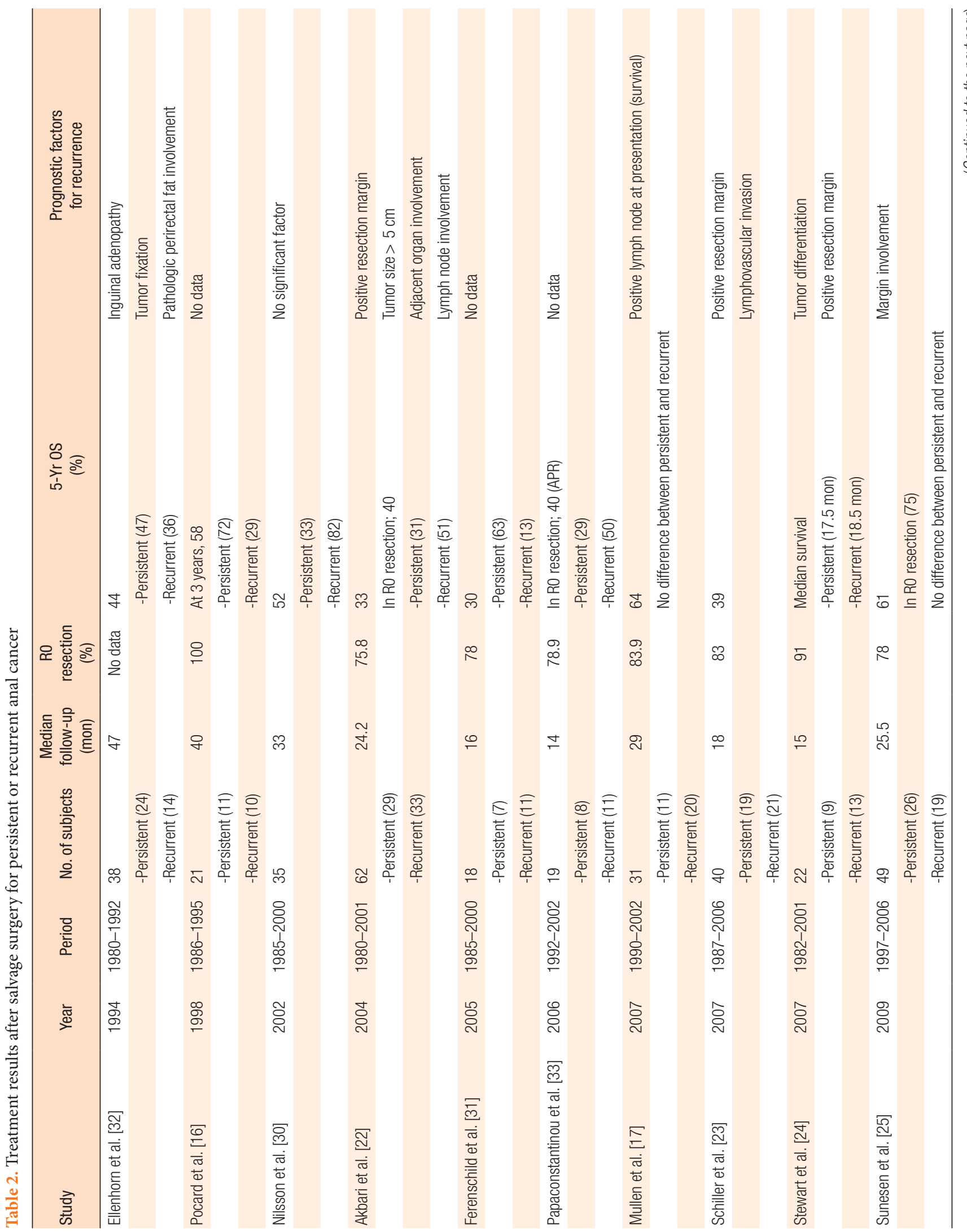




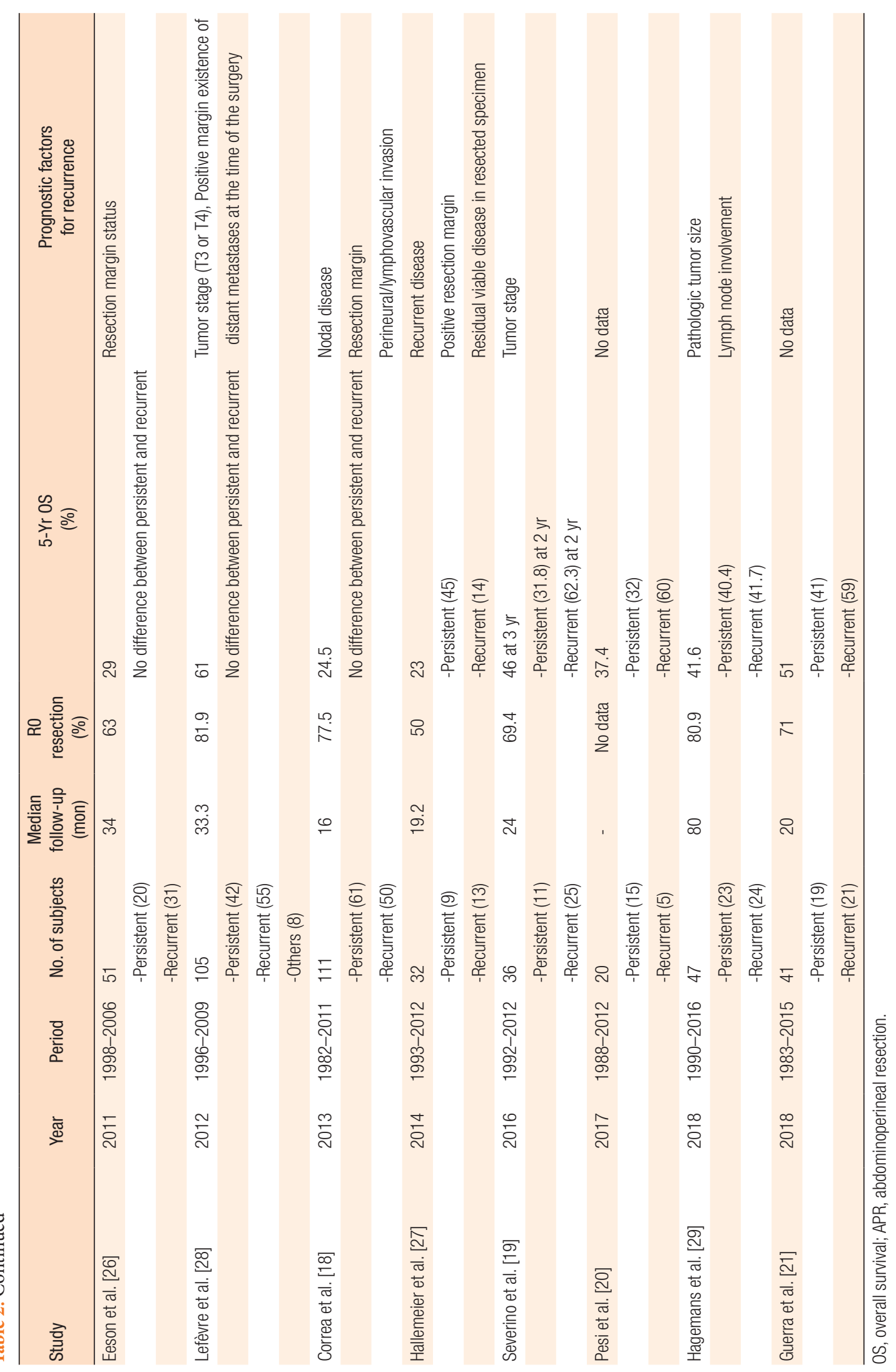


treatment of SCC. Current practice parameters and guidelines do not endorse the routine use of any imaging strategy for local surveillance in the posttreatment surveillance period but suggest consideration in select cases such as advanced tumors or nodal disease pretreatment [34]. Patients are re-evaluated using digital rectal examination (DRE) between 8 and 12 weeks after completion of CXRT. Annual chest, abdominal, and pelvic computed tomography (CT) with contrast is recommended for 3 years for patients who initially had locally advanced disease or node-positive cancers.

In many institutions, follow-up reported beginning 6 to 12 weeks after completion of treatment although the presence of improved but persistent disease at 6 or 12 weeks does not preclude the potential for continued treatment response and subsequent remission [16-21]. Patients should be followed since early intervention for persistent disease and recurrent locoregional disease can lead to successful salvage therapy. Some institutions perform examinations every 3 to 6 months with DRE, anoscopy with biopsy of any suspicious lesion, inguinal examination, and crosssectional imaging with CT scan to rule out distant or regional recurrence $[17,18,35,36]$.

The decision to perform biopsies after completion of CXRT should be based on clinical evaluation. Tumor response to initial CXRT may continue for months following completion of CXRT. In fact, there is no need for routine biopsy if the tumor is clinically improving. Patients should be followed closely with DRE and proctoscopy until either they have a complete clinical response or an abnormal or nonhealing area is identified. An examination under anesthesia with biopsy should then be performed to make the diagnosis.

Patterns of recurrence after primary treatment for anal cancer may be categorized as local, regional, or distant. Patients without clinical resolution of anal cancer following completion of primary therapy should be considered primary treatment failures rather than recurrences. Regional recurrence is defined as metastatic tumor recurrence at pelvic LNs, mesorectum including the sacrum, or inguinal LNs. The most common site of failure is local, occurring in approximately $10 \%$ to $30 \%$ of patients following modern treatment regimens although regional and distant failures (15\% to $20 \%$ ) remain significant problems $[2,3,6,10]$.

Patients with isolated locoregional failure may be candidates for salvage surgery. Histologic confirmation of recurrent or persistent disease should generally be obtained prior to salvage surgery. If biopsies confirm persistent or recurrence disease and distant metastasis has been excluded, then radical salvage surgery is recommended. Some authors have advocated for the use of endorectal ultrasonography (ERUS) to improve the early detection of recurrence $[37,38]$; however, we have not found it helpful in our practice as it is often not possible to distinguish the post-radiotherapy treatment changes from persistent or recurrent disease. Patients should be restaged with a CT scan of the chest, abdomen, and pelvis as it is more sensitive in identifying regional sites of failure than ERUS and can effectively evaluate distant disease. Magnetic resonance imaging is very useful for assessing the local extent of tumor involvement and resectability (Fig. 1). 18Fluoro-deoxyglucose positron emission tomography (PET) scans may be helpful for the further evaluation of indeterminate findings on CT or PET, or for the identification of occult metastases (Fig. 2); however, it has limited utility in the routine evaluation of patients to detect or further workup documented recurrent disease. Limited experienced has been reported on the role of PET or PET/CT in diagnosis and follow-up of anal cancer especially in diagnosis of suspected recurrence. Results of previous studies are discordant about the utility of PET for detection of LN involvement or recurrent disease. Although some authors have reported that PET is superior to conventional imaging for the detection of $\mathrm{LN}$ involvement or suspected recurrence and can result in a change of the treatment plan $[39,40]$, others have not been able to reproduce these advantages [41]. Part of the limitations for the use of PET/ $\mathrm{CT}$ is the difficulty in differentiating post-radiation inflammatory change and the lack of sensitivity for small lesions which results in false-negative reassurance.

\section{SALVAGE SURGERY FOR PERSISTENT OR RECURRENT DISEASE}

\section{Principles of salvage surgery}

Historically APR was the main treatment of anal SCC; however, as a result of the efficacy of combined modality CXRT, surgical resection is reserved for patients with persistent or recurrent disease. The goals of salvage resection for persistent or recurrent anal canal cancer include local control and prevention of distant disease recurrence. Therefore, the principles of surgical therapy include resection of the primary tumor mass with en bloc resection of involved adjacent organs to achieve negative surgical margins and with radical resection of regional LNs including the mesorectum. Positive resection margins are the most reliable predictive factor for recurrence and survival in many studies [18, 22-27]; therefore, careful patient selection with good preoperative imaging and to exclude disseminated disease is critical.

The ability to achieve a negative resection margin is a primary determinant of recurrence risk and long-term local morbidity. R0 resections should be aggressively pursued with wide en bloc resections including the perianal skin and employment of multivisceral or composite sacral resection as required. Due to the anatomic proximity of the vagina and the difficulty in achieving a wide margin of resection along the perineum and rectovaginal septum with complete vagina preservation, recurrences along the posterior vaginal wall and residual septum are common in women after primary APR [18, 21, 27-29]. In addition, the vagina and vulva are also uniquely susceptible to HPV related malignancy. In order to achieve complete resection and minimize the risk for margin positivity, in many cases, we have therefore advocated partial posterior vaginectomy with vertical rectus abdominis myocutaneous 


\section{$\begin{array}{rr}\text { Annals of } & \text { Survival and Operative Outco } \\ \text { Coloproctology } & \text { In Ja Park and George Chang }\end{array}$}
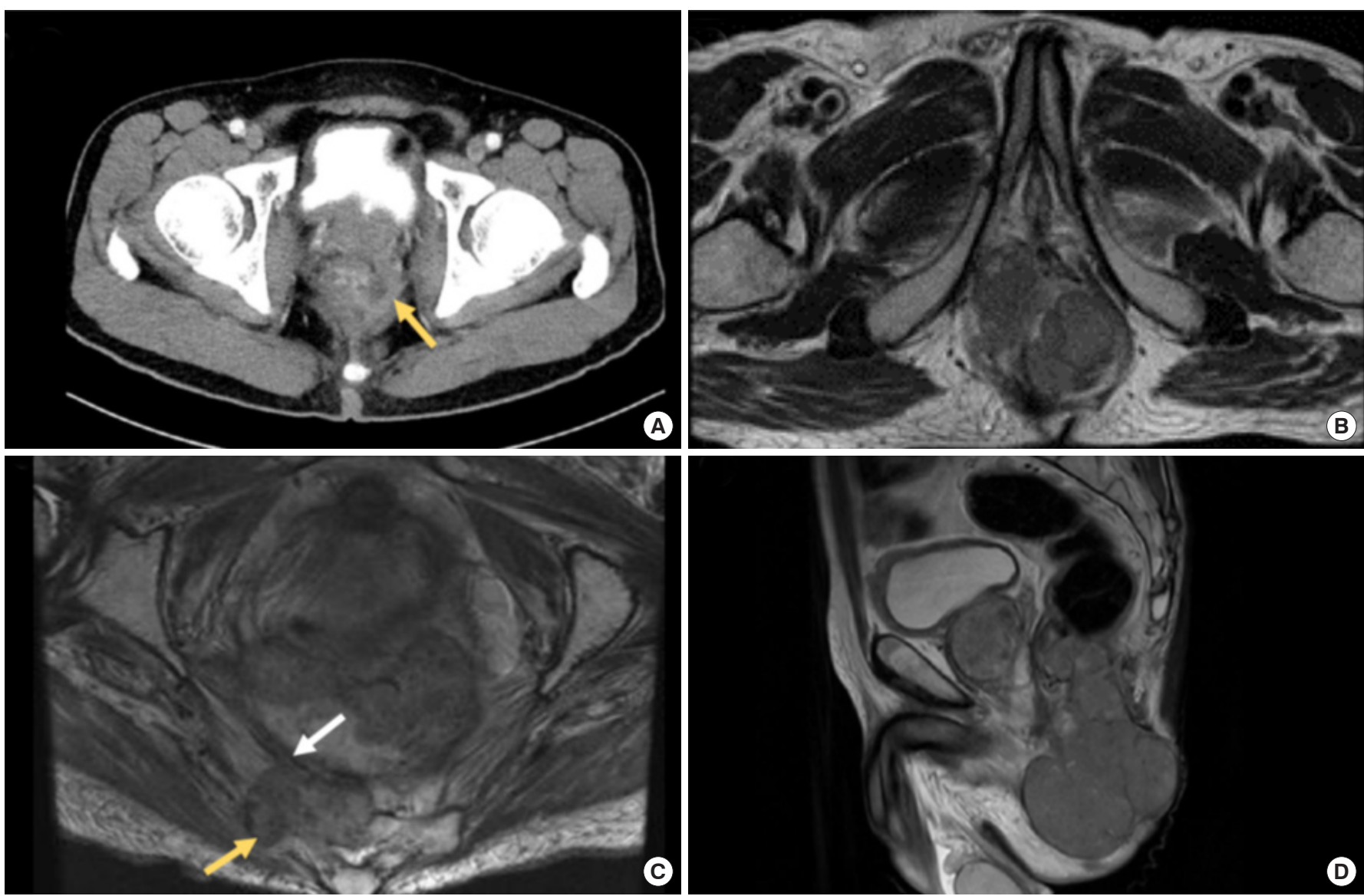

Fig. 1. Locally recurrent anal cancer. (A) Computed tomography scan showing recurrent anal carcinoma invading levator muscle (yellow arrow). (B) Magnetic resonance imaging (MRI) demonstrating recurrent mass within pelvic cavity. (C) MRI shows mass invading pelvic floor (white arrow) and invading outside the pelvis into subgluteal plane (yellow arrow). (D) MRI sagittal view shows invasion into perianal soft tissue.

(VRAM) flap reconstruction during salvage surgery for recurrent anal cancer [17].

In some cases, anal SCC invades the dermal lymphatics leading to malignant obstruction of the normal drainage pathways. Such cases often also present with inguinal metastases and may have in-transit lymphatic disease. Surgical salvage in these patients is particularly challenging as it is often not possible to predict dermal lymphatic invasion based on preoperative histopathologic or radiographic workup.

\section{Oncologic outcomes of salvage surgery}

Despite the performance of salvage APR, survival after failed CXRT is poor. Five-year overall survival after salvage APR range from 23\% to 64\% (Table 2). However, failure of CXRT may denote biological aggressiveness, and even after an apparent technically complete resection, the risk for re-recurrence is significant. The most common pattern of failure after salvage surgery for anal cancer is locoregional. Therefore, careful patient selection based on the ability to achieve a complete resection is essential to maxi- mize benefit and minimize harm.

Whether overall survival was different between persistent and recurrent disease has been reported inconsistently (Table 2). Although some studies reported significant difference in overall survival between persistent and recurrent disease $[16,19,27,30$, 31], most studies showed similar results between 2 indications of salvage surgery.

Given the wide variation in outcomes of salvage surgery for anal cancer, a number of studies have attempted to analyze factors associated with outcomes after salvage therapy. The most commonly identified negative prognostic factor is tumor involvement of the resection margins. Therefore, the achievement of an R0 resection through careful selection of patients by preoperative imaging study and extensive radical resection is essential for improving outcomes of salvage surgery. This factor has been associated not only with impaired local control but also with decreased overall and disease-free survival. Other relevant factors associated with survival are LN involvement, total radiation dose during primary therapy, tumor differentiation, tumor size, and patient age. 


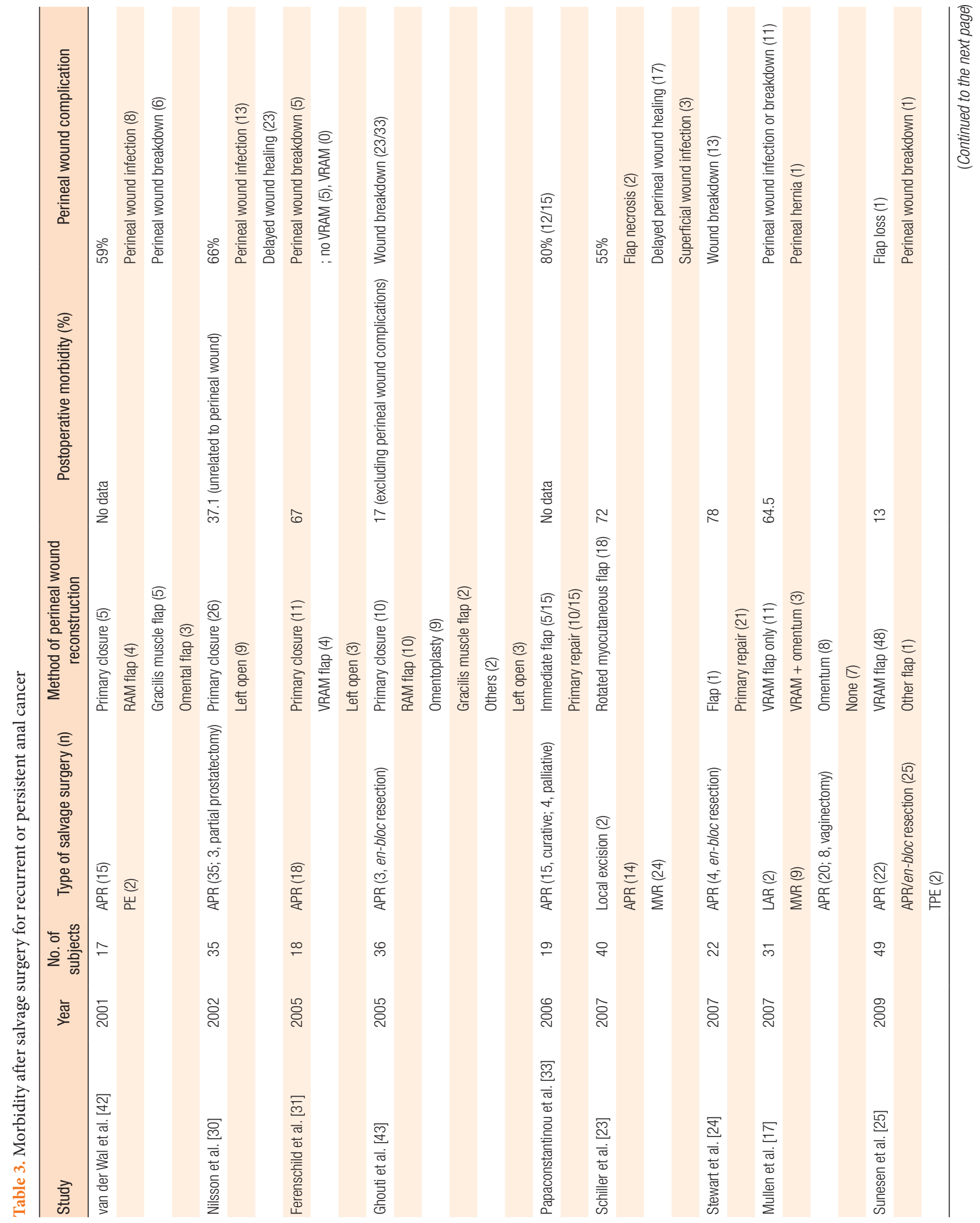




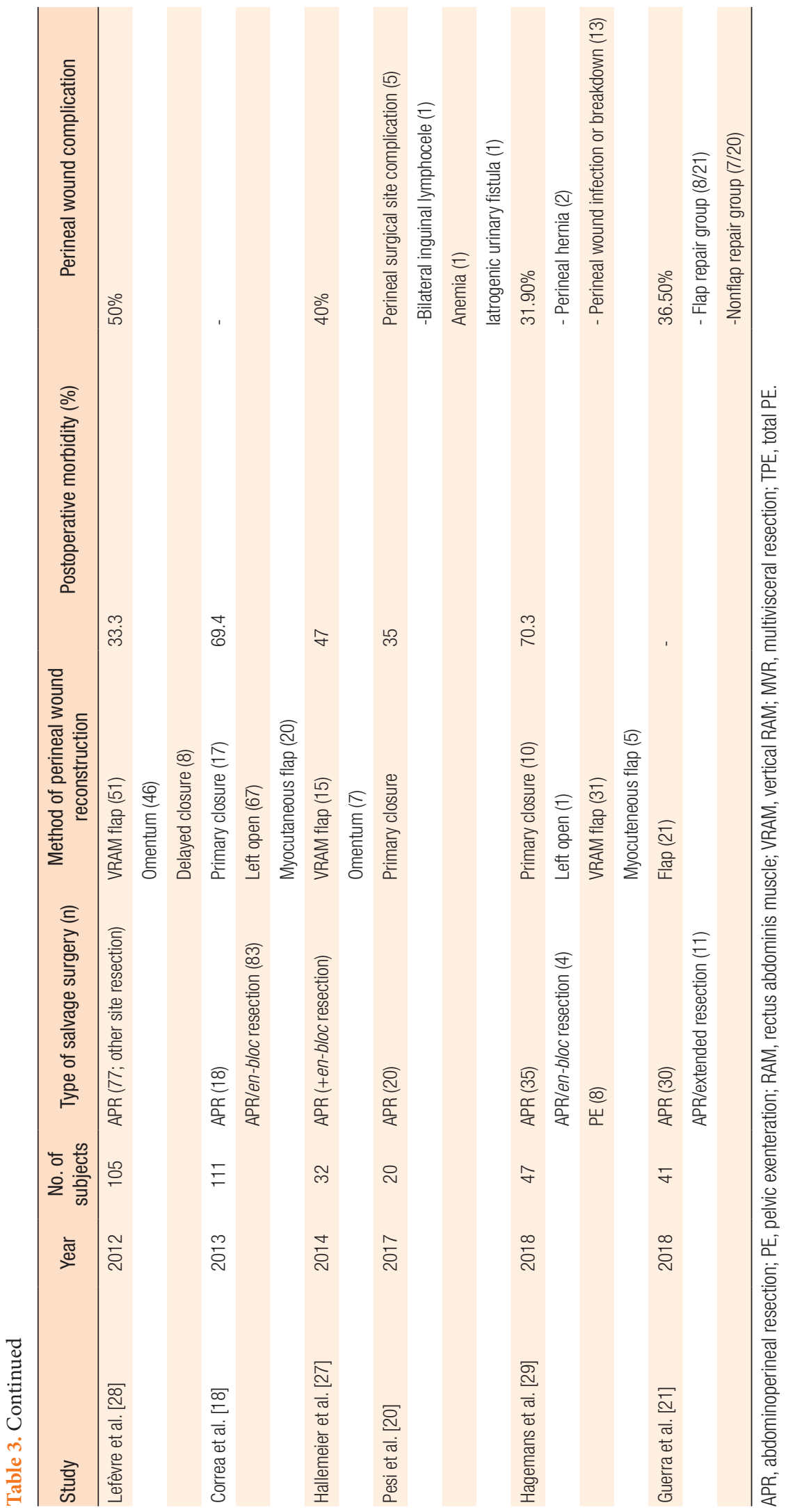




\section{Perioperative outcomes and morbidity of salvage surgery}

Given the complexity and extensiveness of surgery within a previously heavily irradiated field, there is a significant risk for postoperative morbidity in patients undergoing salvage resection Table $3[17,18,20-25,27-31,33,42,43]$. The incidence of local wound complications is high following salvage APR for recurrent or persistent anal cancer and generally higher than is observed with resections for rectal adenocarcinoma. These differences may be due to the higher radiation doses, expanded radiation fields to include a higher dose to the perianal region, as well as to the remote timing of the resection relative to radiation therapy with resultant higher degree of post-radiation fibrosis.

After primary closure of the perineum, dehiscence or infection has been reported in $27 \%$ to $64 \%$ of cases, and perineal healing is often delayed beyond 3 months $[16,31,32,42,43]$. In an effort to decrease wound-related morbidity, several reconstructive options have been proposed to report to promote perineal healing and reduce the incidence and severity of wound complications after salvage pelvic surgery. With the use of muscle or myocutaneous flap reconstruction, improved rates and/or severity of perineal wound complications have been reported [21, 25, 27, 29]. Sunesen et al. [25] reported improved perineal wound complication using VRAM flap in a cohort of 49 patients who underwent salvage surgery for recurrent or persistent anal cancer. There were no major perineal wound complications in the VRAM group (48 of the 49 included patients), but half of the patients (24 of 48) experienced minor perineal wound complications requiring non-surgical management. Another non-randomized comparative study found significantly lower rates of perineal wound complications following salvage APR with myocutaneous flap reconstruction versus primary closure ( $0 \%$ with flap vs. $46 \%$ to $63 \%$ without flap) [44]. This is in contrast to others who have reported major complication rates as high as $40 \%$ without primary flap reconstruction $[21,27,28]$. Although it is not for anal cancer, a randomized controlled trial that compares primary perineal wound closure to VRAM reconstruction in regard to abdominal and perineal wound complications was conducted. A total of 60 patients who received APR for low rectal cancer were enrolled and randomized to VRAM or no VRAM reconstruction group. The perineal wound complications were significantly lower in the VRAM group ( $16.7 \%$ vs. $46.7 \%, \mathrm{P}=0.015$ ) [45]. There is growing evidence to support perineal reconstruction using a VRAM flap after salvage surgery for anal SCC. Another potential option is the gracilis muscle or myocutaneous flap, although it does not provide as much bulk as the rectus muscle-based options. Myocutaneous flap would benefit in terms of filling dead space in the pelvis and may reduce a chance of abscess formation and results in decreased nonhealing chronic wound. Whether to use a myocutaneous flap or not need to be carefully decided considering risks and benefits in terms of individual tumor and general condition.

\section{SALVAGE THERAPY FOR EXTRA- MESORECTAL RECURRENCE}

LN involvement in anal cancer generally follows the pattern of lymphatic drainage of the anal canal which includes the mesorectum and LNs along the superior rectal vessels, the lateral pelvic LNs along the middle rectal vessels and internal iliac system, and the superficial and deep inguinal nodes through the systemic drainage pathways of the anoderm (Fig. 2). Mesorectal excision should be performed for recurrences in perirectal LNs. However, lateral pelvic recurrences along the internal iliac drainage distribution present unique challenges for surgical salvage. As with rectal adenocarcinoma, these recurrences may lead to early involvement of the ureter or sacral nerve roots with associated hydronephrosis, pelvic pain, or autonomic dysfunction. Salvage resection in these circumstances may require resection of the lateral pelvic vessels or sacral nerve roots along with pelvic sidewall structures such as the internal iliac vessels or lateral pelvic LNs.

As with salvage surgery for rectal adenocarcinoma involving the lateral pelvic compartment, the selection of patients for surgical resection should be based on the ability to achieve a complete resection with consideration to the extent of involvement of associated structures such as the iliac bone or sciatic nerve. Resectability in such cases requires careful multidisciplinary review. Patients should be adequately counseled regarding the anticipated recovery and functional ramifications anticipated with the level of resection, particularly when involving levels including S3 and higher (e.g., difficulty with bladder evacuation).

\section{TREATMENT OF INGUINAL LYMPH NODE METASTASIS}

During the primary treatment of anal SCC, to prevent inguinal recurrence, CXRT strategies should include incorporation of the lateral pelvic and inguinal nodal basins into the radiation fields with the addition of a boosting technique for clinically positive LNs. In most circumstances, percutaneous biopsy of suspected nodal disease should be performed to guide treatment. There is approximately a $5 \%$ to $25 \%$ chance of metachronous inguinal LN recurrence particularly in patients with locally advanced (T3 to T4) disease [46]. Prophylactic irradiation of bilateral inguinal regions in normal inguinal nodes can reduce the development of inguinal LN recurrence to less than 5\% [46, 47].

Inguinal involvement usually is unilateral, with bilateral recurrences occurring in less than $5 \%$ as either synchronous or metachronous recurrent disease. The risk of inguinal recurrence may be related to the size and location of the primary tumor with increasing risk associated with increasing $\mathrm{T}$ stage of the primary tumor. The risk is also lower when the entire primary tumor is located above the dentate line and conversely higher when the lymphatic drainage pattern may favor the mesorectal and superior hemorrhoidal route in the tumor involving anal margin, this risk 

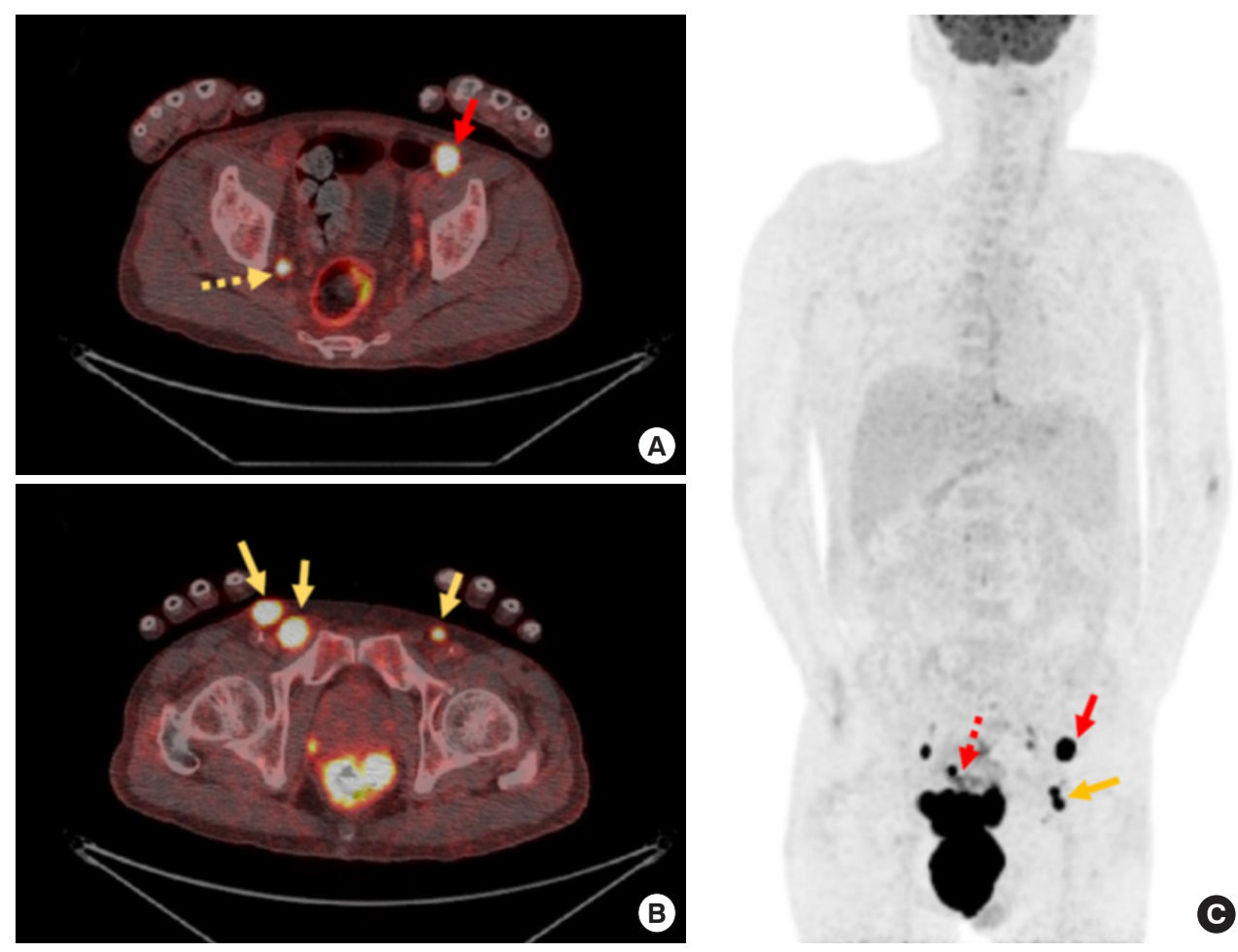

Fig. 2. Variable location of inguinal lymph node metastasis in patients with anal cancer identified in positron emission tomography-computed tomography (PET-CT) scan. (A, B) The cross-sectional PET-CT scans noted both inguinal (yellow arrow), external iliac (red arrow), and lateral pelvic (yellow dotted arrow) lymph nodes. (C) The longitudinal PET-CT scan identifying inguinal (yellow arrow), external iliac (red arrow), and perirectal (red dotted arrow) lymph nodes.

increases considerably.

Because most synchronous LN metastases can be controlled with CXRT, this is the initial treatment of choice. In anal carcinoma, inguinal lymphadenectomy is generally reserved for those patients with disease in the inguinal nodes after CXRT has been completed and prophylactic inguinal dissection is not currently recommended. Pathologic confirmation should be obtained. Sentinel LN biopsy for anal cancer has also been investigated and the feasibility of this approach to anal cancer has been demonstrated $[48,49]$. However, a role for treatment stratification based on sentinel LN biopsy has yet to be established.

When an inguinal recurrence is identified, a review of the initial radiation treatment fields should be performed and treatment initiated with inguinal CXRT if the field has not previously been treated. Salvage treatment options for metachronous disease may include repeat inguinal irradiation if maximal doses of radiation were not delivered versus therapeutic LN dissection. Furthermore, there may be a role for systemic chemotherapy as well. The National Comprehensive Cancer Network released its 2020 guidelines and no longer recommends combined APR and groin dissection for patients with positive inguinal LNs. However, the guidelines still recommend inguinal node dissection for persistent or recurrent disease in the groin despite previous treatment to the groin [34]. Because there exists the potential for serious long-term wound and lower extremity complications after inguinal dissection for anal cancer, the decision to proceed with surgical treatment should be individualized [50-52]. There is little data to guide the extent of inguinal dissection; limited vs. complete. Standards for extent of inguinal LN dissection have therefore not been established and treatment strategies have ranged from en bloc removal of the entire superficial femoral basin to selective removal of clinically evident disease. Whatever the approach, dissection of inguinal nodes should be performed with attention to meticulous ligation of lymphatic channels and wound drainage to reduce the risk for wound complications.

With appropriate patient selection, therapeutic groin dissection for persistent or recurrent disease can result in 5-year survival rates greater than $50 \%$.

\section{CONCLUSION}

While definitive CXRT is the primary treatment of choice in anal SCC, a subgroup of patients will be identified with persistent or recurrent disease. In these patients, salvage surgery is associated with overall survival rates higher than $60 \%$. The cornerstones of salvage surgical management include histologic confirmation and 
wide en bloc radical resection to achieve negative surgical margins followed by multidisciplinary reconstruction. Inguinal LN disease is responsive to and may be prevented by inguinal radiation at the time of primary tumor treatment; however, salvage LN dissection may be necessary for recurrent disease.

\section{CONFLICT OF INTEREST}

No potential conflict of interest relevant to this article was reported.

\section{REFERENCES}

1. Bray F, Ferlay J, Soerjomataram I, Siegel RL, Torre LA, Jemal A. Global cancer statistics 2018: GLOBOCAN estimates of incidence and mortality worldwide for 36 cancers in 185 countries. CA Cancer J Clin 2018;68:394-424.

2. Ajani JA, Winter KA, Gunderson LL, Pedersen J, Benson AB 3rd, Thomas CR Jr, et al. Fluorouracil, mitomycin, and radiotherapy vs fluorouracil, cisplatin, and radiotherapy for carcinoma of the anal canal: a randomized controlled trial. JAMA 2008;299:191421.

3. Lim F, Glynne-Jones R. Chemotherapy/chemoradiation in anal cancer: a systematic review. Cancer Treat Rev 2011;37:520-32.

4. Welton ML, Sharkey FE, Kahlenberg MS. The etiology and epidemiology of anal cancer. Surg Oncol Clin N Am 2004;13:263-75.

5. Roohipour R, Patil S, Goodman KA, Minsky BD, Wong WD, Guillem JG, et al. Squamous-cell carcinoma of the anal canal: predictors of treatment outcome. Dis Colon Rectum 2008;51:14753.

6. Das P, Bhatia S, Eng C, Ajani JA, Skibber JM, Rodriguez-Bigas $\mathrm{MA}$, et al. Predictors and patterns of recurrence after definitive chemoradiation for anal cancer. Int J Radiat Oncol Biol Phys 2007;68:794-800.

7. Daling JR, Madeleine MM, Johnson LG, Schwartz SM, Shera KA, Wurscher MA, et al. Human papillomavirus, smoking, and sexual practices in the etiology of anal cancer. Cancer 2004;101:270-80.

8. Cornall AM, Roberts JM, Garland SM, Hillman RJ, Grulich AE, Tabrizi SN. Anal and perianal squamous carcinomas and highgrade intraepithelial lesions exclusively associated with "low-risk" HPV genotypes 6 and 11. Int J Cancer 2013;133:2253-8.

9. Mai S, Welzel G, Ottstadt M, Lohr F, Severa S, Prigge ES, et al. Prognostic relevance of HPV infection and p16 overexpression in squamous cell anal cancer. Int J Radiat Oncol Biol Phys 2015;93: 819-27.

10. Wright JL, Patil SM, Temple LK, Minsky BD, Saltz LB, Goodman KA. Squamous cell carcinoma of the anal canal: patterns and predictors of failure and implications for intensity-modulated radiation treatment planning. Int J Radiat Oncol Biol Phys 2010;78: 1064-72.

11. Northover J, Glynne-Jones R, Sebag-Montefiore D, James R, Meadows $\mathrm{H}$, Wan S, et al. Chemoradiation for the treatment of epidermoid anal cancer: 13-year follow-up of the first randomised UKCCCR Anal Cancer Trial (ACT I). Br J Cancer 2010; 102:1123-8.

12. Glynne-Jones R, Kadalayil L, Meadows HM, Cunningham D, Samuel L, Geh JI, et al. Tumour- and treatment-related colostomy rates following mitomycin $\mathrm{C}$ or cisplatin chemoradiation with or without maintenance chemotherapy in squamous cell carcinoma of the anus in the ACT II trial. Ann Oncol 2014;25:1616-22.

13. Bartelink H, Roelofsen F, Eschwege F, Rougier P, Bosset JF, Gonzalez DG, et al. Concomitant radiotherapy and chemotherapy is superior to radiotherapy alone in the treatment of locally advanced anal cancer: results of a phase III randomized trial of the European Organization for Research and Treatment of Cancer Radiotherapy and Gastrointestinal Cooperative Groups. J Clin Oncol 1997;155:2040-9.

14. Flam M, John M, Pajak TF, Petrelli N, Myerson R, Doggett S, et al. Role of mitomycin in combination with fluorouracil and radiotherapy, and of salvage chemoradiation in the definitive nonsurgical treatment of epidermoid carcinoma of the anal canal: results of a phase III randomized intergroup study. J Clin Oncol 1996;14:2527-39.

15. Conroy T, Ducreux M, Lemanski C. Treatment intensification by induction chemotherapy (ICT) and radiation dose escalation in locally advanced squamous cell anal canal carcinoma (LAAC): definitive analysis of the intergroup ACCORD-03 trial. J Clin Oncol 2009;27:176s (Abstract 4033).

16. Pocard M, Tiret E, Nugent K, Dehni N, Parc R. Results of salvage abdominoperineal resection for anal cancer after radiotherapy. Dis Colon Rectum 1998;41:1488-93.

17. Mullen JT, Rodriguez-Bigas MA, Chang GJ, Barcenas $\mathrm{CH}$, Crane $\mathrm{CH}$, Skibber JM, et al. Results of surgical salvage after failed chemoradiation therapy for epidermoid carcinoma of the anal canal. Ann Surg Oncol 2007;14:478-83.

18. Correa JH, Castro LS, Kesley R, Dias JA, Jesus JP, Olivatto LO, et al. Salvage abdominoperineal resection for anal cancer following chemoradiation: a proposed scoring system for predicting postoperative survival. J Surg Oncol 2013;107:486-92.

19. Severino NP, Chadi SA, Rosen L, Coiro S, Choman E, Berho M, et al. Survival following salvage abdominoperineal resection for persistent and recurrent squamous cell carcinoma of the anus: do these disease categories affect survival? Colorectal Dis 2016;18: 959-66.

20. Pesi B, Scaringi S, Di Martino C, Batignani G, Giudici F, Bisogni D, et al. Results of surgical salvage treatment for anal canal cancer: a retrospective analysis with overview of the literature. Dig Surg 2017;34:380-6.

21. Guerra GR, Kong JC, Bernardi MP, Ramsay RG, Phillips WA, Warrier SK, et al. Salvage surgery for locoregional failure in anal squamous cell carcinoma. Dis Colon Rectum 2018;61:179-86.

22. Akbari RP, Paty PB, Guillem JG, Weiser MR, Temple LK, Minsky $\mathrm{BD}$, et al. Oncologic outcomes of salvage surgery for epidermoid carcinoma of the anus initially managed with combined modality 
therapy. Dis Colon Rectum 2004;47:1136-44.

23. Schiller DE, Cummings BJ, Rai S, Le LW, Last L, Davey P, et al. Outcomes of salvage surgery for squamous cell carcinoma of the anal canal. Ann Surg Oncol 2007;14:2780-9.

24. Stewart D, Yan Y, Kodner IJ, Birnbaum E, Fleshman J, Myerson R, et al. Salvage surgery after failed chemoradiation for anal canal cancer: should the paradigm be changed for high-risk tumors? J Gastrointest Surg 2007;11:1744-51.

25. Sunesen KG, Buntzen S, Tei T, Lindegaard JC, Nørgaard M, Laurberg S. Perineal healing and survival after anal cancer salvage surgery: 10-year experience with primary perineal reconstruction using the vertical rectus abdominis myocutaneous (VRAM) flap. Ann Surg Oncol 2009;16:68-77.

26. Eeson G, Foo M, Harrow S, McGregor G, Hay J. Outcomes of salvage surgery for epidermoid carcinoma of the anus following failed combined modality treatment. Am J Surg 2011;201:628-33.

27. Hallemeier CL, You YN, Larson DW, Dozois EJ, Nelson H, Klein KA, et al. Multimodality therapy including salvage surgical resection and intraoperative radiotherapy for patients with squamouscell carcinoma of the anus with residual or recurrent disease after primary chemoradiotherapy. Dis Colon Rectum 2014;57:442-8.

28. Lefèvre JH, Corte H, Tiret E, Boccara D, Chaouat M, Touboul E, et al. Abdominoperineal resection for squamous cell anal carcinoma: survival and risk factors for recurrence. Ann Surg Oncol 2012;19:4186-92.

29. Hagemans JA, Blinde SE, Nuyttens JJ, Morshuis WG, Mureau MA, Rothbarth J, et al. Salvage abdominoperineal resection for squamous cell anal cancer: a 30-year single-institution experience. Ann Surg Oncol 2018;25:1970-9.

30. Nilsson PJ, Svensson C, Goldman S, Glimelius B. Salvage abdominoperineal resection in anal epidermoid cancer. Br J Surg 2002; 89:1425-9.

31. Ferenschild FT, Vermaas M, Hofer SO, Verhoef C, Eggermont AM, de Wilt JH. Salvage abdominoperineal resection and perineal wound healing in local recurrent or persistent anal cancer. World J Surg 2005;29:1452-7.

32. Ellenhorn JD, Enker WE, Quan SH. Salvage abdominoperineal resection following combined chemotherapy and radiotherapy for epidermoid carcinoma of the anus. Ann Surg Oncol 1994;1: 105-10.

33. Papaconstantinou HT, Bullard KM, Rothenberger DA, Madoff RD. Salvage abdominoperineal resection after failed Nigro protocol: modest success, major morbidity. Colorectal Dis 2006;8:124-9.

34. Benson AB, Venook AP, Al-Hawary MM, Cederquist L, Chen YJ, Ciombor KK, et al. Anal Carcinoma, Version 2.2018, NCCN Clinical Practice Guidelines in Oncology. J Natl Compr Canc Netw 2018;16:852-71.

35. Cunin L, Alfa-Wali M, Turner J, Bower M, Ion L, Allen-Mersh T. Salvage surgery for residual primary and locally recurrent anal squamous cell carcinoma after chemoradiotherapy in HIV-positive individuals. Ann Surg Oncol 2014;21:527-32.

36. Mariani P, Ghanneme A, De la Rochefordière A, Girodet J, Falcou
MC, Salmon RJ. Abdominoperineal resection for anal cancer. Dis Colon Rectum 2008;51:1495-501.

37. Christensen AF, Nielsen MB, Svendsen LB, Engelholm SA. Threedimensional anal endosonography may improve detection of recurrent anal cancer. Dis Colon Rectum 2006;49:1527-32.

38. Peterson CY, Weiser MR, Paty PB, Guillem JG, Nash GM, GarciaAguilar J, et al. Does endoscopic ultrasound improve detection of locally recurrent anal squamous-cell cancer? Dis Colon Rectum 2015;58:193-8.

39. Mistrangelo M, Pelosi E, Bellò M, Ricardi U, Milanesi E, Cassoni P, et al. Role of positron emission tomography-computed tomography in the management of anal cancer. Int J Radiat Oncol Biol Phys 2012;84:66-72.

40. Dapper H, Schiller K, Münch S, Peeken JC, Borm K, Weber W, et al. Have we achieved adequate recommendations for target volume definitions in anal cancer?: a PET imaging based patterns of failure analysis in the context of established contouring guidelines. BMC Cancer 2019;19:742.

41. Manafi-Farid R, Kupferthaler A, Wundsam H, Gruber G, Vali R, Venhoda C, et al. Additional value of 2-[18F]FDG PET/CT comparing to MRI in treatment approach of anal cancer patients. J Clin Med 2020;9:2715.

42. van der Wal BC, Cleffken BI, Gulec B, Kaufman HS, Choti MA. Results of salvage abdominoperineal resection for recurrent anal carcinoma following combined chemoradiation therapy. J Gastrointest Surg 2001;5:383-7.

43. Ghouti L, Houvenaeghel G, Moutardier V, Giovannini M, Magnin $\mathrm{V}$, Lelong B, et al. Salvage abdominoperineal resection after failure of conservative treatment in anal epidermoid cancer. Dis Colon Rectum 2005;48:16-22.

44. Tei TM, Stolzenburg T, Buntzen S, Laurberg S, Kjeldsen H. Use of transpelvic rectus abdominis musculocutaneous flap for anal cancer salvage surgery. Br J Surg 2003;90:575-80.

45. Touny A, Othman H, Maamoon S, Ramzy S, Elmarakby H. Perineal reconstruction using pedicled vertical rectus abdominis myocutaneous flap (VRAM). J Surg Oncol 2014;110:752-7.

46. Ortholan C, Resbeut M, Hannoun-Levi JM, Teissier E, Gerard JP, Ronchin P, et al. Anal canal cancer: management of inguinal nodes and benefit of prophylactic inguinal irradiation (CORS-03 Study). Int J Radiat Oncol Biol Phys 2012;82:1988-95.

47. Tomaszewski JM, Link E, Leong T, Heriot A, Vazquez M, Chander S, et al. Twenty-five-year experience with radical chemoradiation for anal cancer. Int J Radiat Oncol Biol Phys 2012;83:552-8.

48. De Nardi P, Carvello M, Staudacher C. New approach to anal cancer: individualized therapy based on sentinel lymph node biopsy. World J Gastroenterol 2012;18:6349-56.

49. De Nardi P, Mistrangelo M, Burtulo G, Passoni P, Slim N, Ronzoni $\mathrm{M}$, et al. Tailoring the radiotherapy approach in patients with anal squamous cell carcinoma based on inguinal sentinel lymph node biopsy. J Surg Oncol 2020;123:315-21.

50. Contreras N, Jakub JW. The achilles heel of minimally invasive inguinal lymph node dissection: seroma formation. Am J Surg 
2020;219:696-700.

51. Cesmebasi A, Baker A, Du Plessis M, Matusz P, Shane Tubbs R, Loukas $\mathrm{M}$. The surgical anatomy of the inguinal lymphatics. Am Surg 2015;81:365-9.
52. Chang SB, Askew RL, Xing Y, Weaver S, Gershenwald JE, Lee JE, et al. Prospective assessment of postoperative complications and associated costs following inguinal lymph node dissection (ILND) in melanoma patients. Ann Surg Oncol 2010;17:2764-72. 